\title{
The influence of the preparation methods on the inclusion of model drugs in a $\beta$-cyclodextrin cavity
}

\author{
P.J. Salústio a ${ }^{\text {a G. Feio }}{ }^{\text {b, c }}$, J.L. Figueirinhas ${ }^{\text {c, }}$ \\ J.F. Pinto ${ }^{\text {a }}$ H.M. Cabral Marques ${ }^{\text {a,* }}$
}

\footnotetext{
${ }^{a} i$ Med.UL (Research Institute for Medicines and Pharmaceutical Sciences), Faculdade de Farmácia da Universidade de Lisboa, Av. Prof. Gama Pinto, P-1649-003 Lisboa, Portugal

${ }^{b}$ Dep. Ciência de Materiais, CENIMAT/I3N, Faculdade de Ciências e Tecnologia da Universidade Nova de Lisboa, Campus da Caparica, 2829-516 Caparica, Portugal

${ }^{c}$ CFMC/UL Av. Prof. Gama Pinto 2, 1649-001 Lisboa, Portugal
}

Running head: Inclusion of a drug in a $\beta$-cyclodextrin cavity

*Corresponding author.

$i$-MED, Faculdade de Farmácia da Universidade de Lisboa

Av. Prof. Gama Pinto

1649 - 003 Lisboa

E-mail address: hcmarques@ff.ul.pt

Tel.: 00351217946427

Fax: 00351217946434 


\begin{abstract}
The work aims to prove the complexation of two models drugs (ibuprofen, IB and indomethacin, IN) by beta-cyclodextrin $(\beta \mathrm{CD})$, the effect of the water in such process, and the comparison of their complexation yields. Two methods were considered: kneading of a binary mixture of the drug: $\beta \mathrm{CD}$ and inclusion of either IB or IN in aqueous solutions of $\beta \mathrm{CD}$. In the latter method the water was removed by air stream, spray-drying and freeze-drying. To prove the formation of complexes in final products optical microscopy, UV spectroscopy, IR spectroscopy, DSC, X-Ray and NMR were considered. Each powder was added to an acidic solution $(\mathrm{pH}=2)$ to quantify the concentration of the drug inside $\beta \mathrm{CD}$ cavity. Others media ( $\mathrm{pH}=5$ and 7) were used to prove the existence of drug not complexed in each powder as the drugs solubility increases with the $\mathrm{pH}$. It was observed that complexation occurred in all powders, and that the fraction of drug inside the $\beta C D$ did not depend neither on the method of complexation nor on the processes of drying considered.
\end{abstract}

Keywords: Ibuprofen, Indomethacin, Cyclodextrin, Freeze-drying, Spray-drying, Physical mixture, Kneading, NMR, Optical microscopy, FT-IR spectroscopy, UV spectroscopy, DSC 


\section{Introduction}

The therapeutic activity of drugs is related to their solubility in water. To improve the solubility of a drug, various techniques can be considered namely micronisation, nanosizing, microemulsification, formulation in an amorphous solid form (e.g. solid dispersions by melt extrusion) or the modification of the physicochemical properties of the drug (e.g. salt formation and water soluble complexes formation) $[1,2]$.

Cyclodextrins (CDs) are cyclic oligosaccharides with a lipophilic cavity and a hydrophilic outer surface which contain $6(\alpha), 7(\beta)$ and $8(\gamma)$ glucose units with different solubilities which can be further improved by chemical modifications on its molecular structure. These compounds have the ability to form inclusion complexes by taking up a whole molecule or rather some non polar parts in its hydrophobic cavity [3-9]. The driving forces between hosts and drugs which have been proposed to justify the complex formation are hydrogen bonds, van der Waals forces, hydrophobic interactions and the release of "high energy water" molecules from the cavity [10]. During the drug- $\beta \mathrm{CD}$ complex formation no covalent bonds are formed or broken which stresses the physical rather than chemical nature of the process [1]. The complexes improve the characteristics of the drugs such as solubility, chemical stability (due to hydrolysis, oxidation, photodecomposition and dehydration of the drug), bioavailability and reduction of drugs side effects $[1,10]$. A number of different methods have been applied to enhance the complex efficiency of the CDs: ionization of the drug, salt formation, formation of the metal complexes and addition of organic cosolvents to the aqueous complexation media and the use of supercritical fluids all promote the enhancement of the intrinsic solubility of the drug-favouring complexation $[3,9,11]$.

The model drugs used in this study were NSAIDs: ibuprofen $\left(\mathrm{pK}_{\mathrm{a}}\right.$ value of 4.4) and indomethacin $\left(\mathrm{pK}_{\mathrm{a}}\right.$ value of 4.5$)$ which is known to exist in more than one nosolvated crystalline modification (three polymorphs $\alpha, \beta, \gamma$ ). Both drugs are $\mathrm{pH}-$ dependent and practically insoluble in water [12-15]. These drugs were selected due to their low solubility and high permeability (Class II, Biopharmaceutical Classification System, BSC [16]) and thus the increase on their solubility will improve their bioavailability.

The aim of this work is to provide evidence that the yield of complex formation between $\beta C D$ and two NSAIDs do not depend on the amount of water used in the preparation of the solid complexes by kneading or solution/suspension methods used. In the solution/suspension method of complexation, water was removed by spray-drying (SD), freeze-drying (FD), and air stream drying (AS), as described by Miller et al [17]. 


\section{Materials and methods}

\subsection{Materials}

( \pm )-Ibuprofen 20/35, (racemic $\alpha$-methyl-4-[2-methylpropyl] benzene acetic acid, IB) and Indomethacin (1-(p-chlorobenzoyl)-5-methoxy-2-methylindole-3-acetic acid, IN) were purchased from Capsifar (Portugal). $\beta$-cyclodextrin $(\beta \mathrm{CD})$ was purchased from Wacker (Germany). Demineralised water $(\mathrm{pH}=4.5-5.0)$ was used in the study.

\subsection{Methods}

\subsection{1. - Phase Solubility Studies}

Phase solubility studies of the individual components were carried out according to the method of Higuchi and Connors [18]. Aqueous solutions of $\beta \mathrm{CD}$ at different concentrations $\left(0,3,6,9\right.$ and $\left.12 * 10^{-3} \mathrm{M}\right)$ at $\mathrm{pH} \approx 6$, were added to each one of the two drugs, in amounts above their solubility, in capped tubes. The tubes were placed in a water bath at a constant temperature $\left( \pm 25^{\circ} \mathrm{C}\right)$ and were shacken in horizontal movements (100/min) for a period of time to allow equilibrium: 8 hours for the indomethacin and 10 hours for the ibuprofen. After these periods the concentrations did not change. Samples were collected and centrifuged (Sigma 112, B. Braun Biotech International, Germany) at 13,000 r.p.m. (10 min) in eppendorf tubes prior to the quantification of the drug by ultraviolet spectroscopy analysis (U-200, Hitachi, Japan). Phase solubility curves were represented as the total dissolved drug concentration against the concentration of $\beta \mathrm{CD}$. The binding constant $\left(\mathrm{K}_{1: 1}\right)$ for each complex was calculated from the slope of the straight-line portion of the curve, according to the following equation [18]:

$$
K_{1: 1}=\frac{\text { slope }}{S_{0}(1-\text { slope })}
$$

where, $\mathrm{S}_{0}$ is the solubility of the drug in the absence of $\beta \mathrm{CD}$.

\subsection{2. - Preparation of the complexes}

The particle sizes of the materials used in this study were less than $250 \mu \mathrm{m}$. The $\beta \mathrm{CD}$ was dissolved in an amount of water approximately equivalent to its solubility $\left(1.63 \mathrm{M}\right.$ at $\left.25^{\circ} \mathrm{C}\right)$ and each drug was added in $1: 1$ stoichiometric ratio in corresponding amounts to produce $100 \mathrm{~g}$ of the final mixture. The systems of $\beta \mathrm{CD}$ with each drug were shacken ( 250 r.p.m.) at $25 \pm 1^{\circ} \mathrm{C}$ for a pre-determined time ( $8 \mathrm{~h}$ for IN and $10 \mathrm{~h}$ for IB correspond dynamic equilibrium from the solubility studies).

Before removal of water, the $\mathrm{pH}$ value was determined in the supernatant and samples of each suspension were collected for the determination of the drug concentration. Water was removed by spray-drying (SD) (Büchi MiniSpray Dryer B191, Switzerland: inlet temperature $125^{\circ} \mathrm{C}$, outlet temperature $98^{\circ} \mathrm{C}$, aspirator set at $100 \%$ and flow rate set at $2.3 \mathrm{ml} / \mathrm{min}$ ) and by freeze-drying (FD) (Christ Alpha 1-4, B. Braun Biotech International, Germany: samples were previously frozen at $-20^{\circ} \mathrm{C}$ and then dried at 0.0045-0.0070 mbar). In a different set of experiments, drying was performed by exposing the suspensions to a stream of air (AS) at room temperature. A 
physical mixture (PM, regarded as control) and the mixture for kneading (K) were prepared in flasks by shaking them for 10 min (Fisher-Kendall Scientific Co, 12-811, USA). Kneading was carried out by adding water $(20 \mathrm{ml} / 5 \mathrm{~min})(30,70 \%$ - IB and 50 , $70 \%-\mathrm{IN} \mathrm{w} / \mathrm{w}$ ) in a mortar, and the mass was triturated with a pestle. The water in the mixture was removed by evaporation under stirring. The dried binary mixtures obtained by the four methods were sieved $(250 \mu \mathrm{m})$ and, if necessary, the binary mixtures were ground in a mortar with pestle for the production of particles with less than $250 \mu \mathrm{m}$ in diameter.

Samples of the powders (AS, K30, FD for IB and AS, K70, FD for IN) were washed with diethyl ether (Merck, Germany) to remove the drug not complexed in order to confirm the presence of the inclusion complex in the powders [19]. Drugs were identified by ultraviolet spectroscopy (samples with an asterisk).

The preparation of complexes by melting of the components in an oven (Heraeus, Germany) has also been tried. The powders were weighed in $1: 1$ stoichiometric ratio and then placed in an oven (IB- $\beta \mathrm{CD}: 120^{\circ} \mathrm{C}$ and $\mathrm{IN}-\beta \mathrm{CD}$ : $200^{\circ} \mathrm{C}$ ). These temperatures were chosen to assure the melting of the drugs [20].

\subsection{3. - Characterisation of the complexes}

\subsubsection{1. - Optical microscopy (OM)}

Raw materials and all powders were observed through a microscope (Olympus CX40 RF200 coupled with an Olympus C-5050 photographic system 5 megapixels, at 40 and 200 times magnification Olympus, Japan) and the images registered.

\subsubsection{2. - Differential scanning calorimetry (DSC)}

All powders were analysed by DSC (TC 11, TA Processor, Mettler, Germany) to identify their thermal behaviour: 5-6 $\mathrm{mg}$ of each powder in aluminium pans was heated at $5^{\circ} \mathrm{C} / \mathrm{min}$ from 30 up to $300^{\circ} \mathrm{C}$. The powders produced by AS drying, FD and $\mathrm{K}$ were also evaluated for thermal behaviour after being washed with diethyl ether.

\subsubsection{3. - Spectroscopic evaluation}

Ultraviolet spectroscopy (UV): identification of drug (IB and IN) in complexes, previously washed with diethyl ether, was performed by scanning from 380 to $190 \mathrm{~nm}$ (Hitachi U-2000, Japan) and compared to the absorbances of IB (at 221 and $263 \mathrm{~nm}$ ) and IN (at 196, 265 and $319 \mathrm{~nm}$ ) in the complexes with those produced by the free drug.

Fourier Transform Infrared spectroscopy (FT-IR): FT-IR spectra were obtained for each raw material and for the mixtures of powders (Nicolet spectrophotometer, model Impact 400, USA) using a $\mathrm{KBr}$ disk method and scanned in the range of 4000 to $450 \mathrm{~cm}^{-1}$. Furthermore some mixtures were washed with diethyl ether (AS*, FD* and $\mathrm{K}^{*}$ ) and also submitted to characterisation by FT-IR.

Nuclear magnetic resonance (NMR): all the ${ }^{1} \mathrm{H}$ NMR spectra were recorded at $300 \mathrm{MHz}$ (Bruker AVANCE $\mathrm{II}^{+}$spectrometer, Germany). The $\beta \mathrm{CD}$ anomeric proton $\mathrm{H}(1)$ was used as internal reference $(0 \mathrm{ppm})$ for the magnetic shift units, as described in the literature [21], since its location insures the smallest shift and the residual protons in deuterated water are too large and may undergo exchange with small amounts of nondeuterated water [21]. The measurements were performed at $40^{\circ} \mathrm{C}$. 
$X$-ray diffractometry $(X R D)$ : the XRD measurements on the samples from the mixtures of the powders were performed using a variable-geometry device equipped with a Max-Flux Optic graded multilayer monochromator ( $\mathrm{CuK} \alpha$ radiation) and a gas curved counter "INEL CPS 590" that was associated with a data acquisition computercontrolled system. The measurements were performed at room temperature $\left(22^{\circ} \mathrm{C}\right)$.

\subsection{4. - Assay of the drug in the mixtures}

The total drug content (free and in the complex) present in each powder was determined by UV spectrophotometry: $10 \mathrm{mg}$ of each powder was dissolved in $100 \mathrm{ml}$ (IB) or in $250 \mathrm{ml}$ (IN) of a hydroalcoholic solution 1:1 (v/v) in which both are completely dissolved. All solutions produced were submitted to ultrasonication (Branson 5200, USA) for $25 \mathrm{~min}$ to assure a complete dissolution of the drug, i.e., $100 \%$ of the weighted drug.

The inclusion yield (\%) for the drug processed according to the different techniques was assessed at different $\mathrm{pH}$ values ( $\mathrm{pH}=2,5$ and 7 , phosphate buffer) [22]. Samples of $20 \mathrm{mg}$ of the each mixture powder were suspended in $20 \mathrm{ml}$ of phosphate buffer solution, ultrasonicated for $3 \mathrm{~min}$, centrifuged (Megafuge 1.0R, Heraeus, Germany) at $3500 \mathrm{rpm}$ for $15 \mathrm{~min}$ and the dissolved drug in the supernatants was quantified by UV spectrophotometry.

\section{Results and discussion}

\section{1. - Phase solubility}

The dynamic equilibrium was reached up to 8 hours for IN and 10 hours for IB, as determined in the phase solubility studies. These studies showed that, the maximum amount of IB dissolved reached a constant concentration at $6^{*} 10^{-3} \mathrm{M} \beta \mathrm{CD}$, characteristic of a $B_{\mathrm{s}}$ type diagram leading to an insoluble precipitate made of both free and complexed drug (Fig. 1A). On the other hand, the solubility of IN increased linearly with the concentration of $\beta \mathrm{CD}$, characteristic of an $A_{L}$ type solubility diagram [18], i.e., formation a 1:1 complex. In this case, the sediment is only made of drug (Fig. 1B). For IN the apparent stability constant, reflecting the extension of inclusion, was determined taking into consideration all points in the curve $\left(\mathrm{K}_{1: 1}=366 \mathrm{M}^{-1}\right)$, whereas for the IB only the first three points of the curve were considered, i.e., the linear portion $\left(\mathrm{K}_{1: 1}=\right.$ $\left.2016 \mathrm{M}^{-1}\right) . \mathrm{K}_{1: 1}$ values show that the process of the inclusion is easier for IB than IN, that may be partly explained by the fact that the molecular structure of IB is simpler (lower molecular weight and less aromatics groups) than the structure of the IN. 

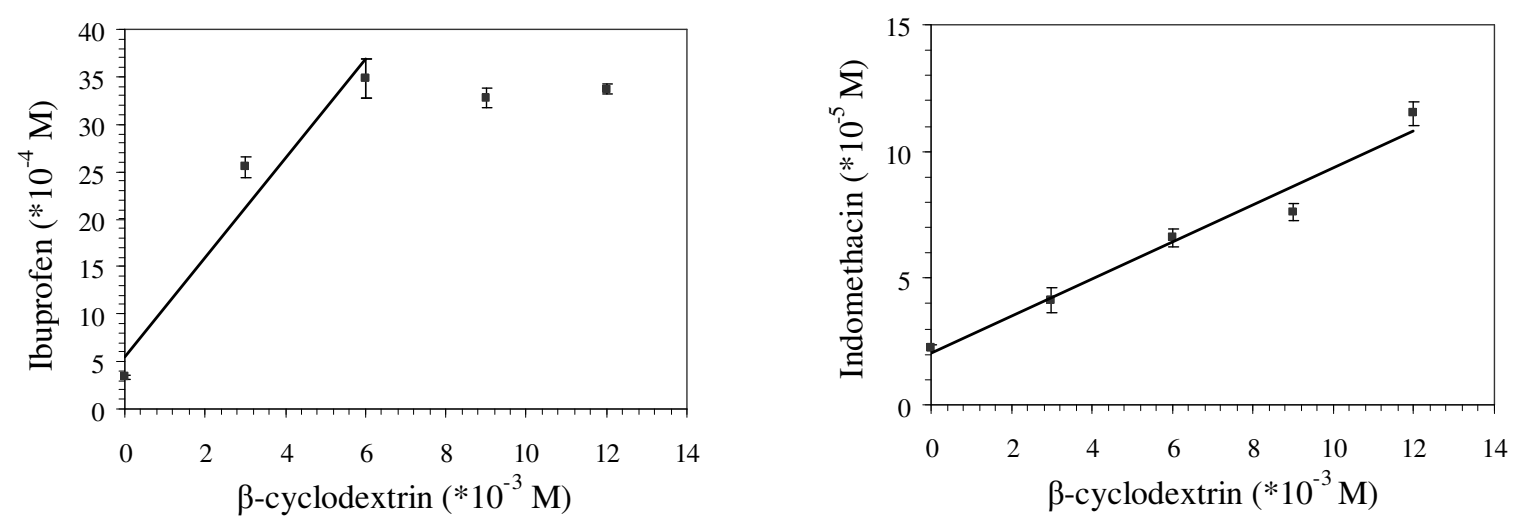

Fig. 1. Phase solubility analysis for A) ibuprofen and B) indomethacin.

\section{2. - Physical aspect}

Throughout and after kneading process, the preparation of powders by the addition of water originates products with different consistencies (Fig. 2): IB- $\beta$ CD K30 was easier to mix than IB- $\beta$ CD K70 (Fig. 2 , $\mathrm{a}_{1}$ versus $\mathrm{a}_{2}$ ); the particles in the first mass agglomerated whereas in the second produced a very hard mass. On the other hand, both IN- $\beta$ CD $\mathrm{K}$ formulations were easily mixed with water ending up in a liquid (Fig. 2, $b_{1}$ versus $b_{2}$ ).

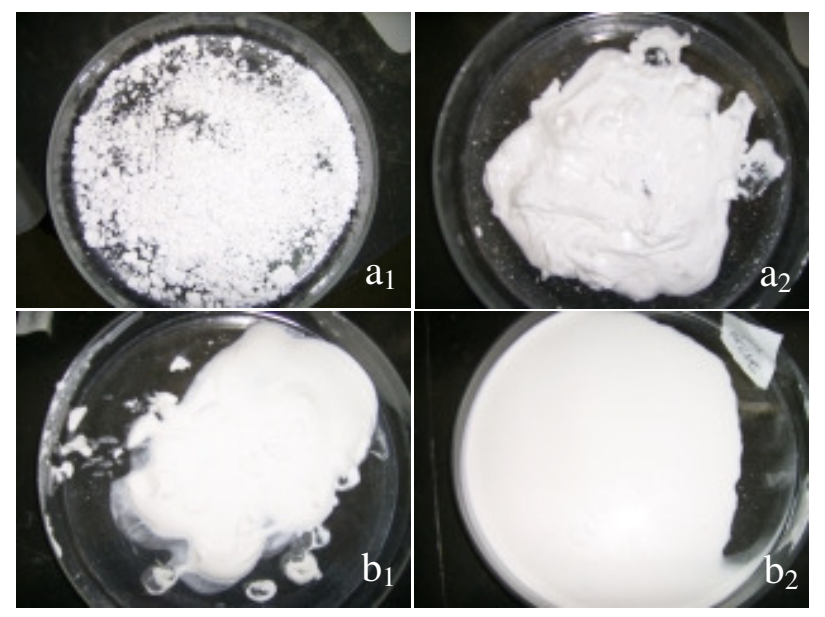

$a_{1}$ ) IB- $\beta C D$ 30\% water; $a_{2}$ ) IB- $\beta C D$ 70\% water; $\mathrm{b}_{1}$ ) IN- $\beta$ CD 50\% water; $\mathrm{b}_{2}$ ) IN- $\beta \mathrm{CD} 70 \%$

Fig. 2. Aspect of the powders produced by kneading at the end of the preparation.

Table 1 presents the results of the fractions of drugs in the supernatant dissolved as complexes of the suspensions, before drying. The value for IB shows that the percentage of the drug- $\beta \mathrm{CD}$ complex dissolved is lower when compared with the values obtained after reconstitution of the dried powder $(26.77 \%$ versus $78.95 \%)$. This might be explained by the partial precipitation of the drug- $\beta C D$ complex (profile $B_{s}$ in the solubility diagram [18]) together with the free drug. By contrast, the values for IN have shown that the percentage of the drug- $\beta \mathrm{CD}$ complex dissolved is comparable to the values obtained after reconstitution of the dried powder $(0.83 \%$ versus $0.95 \%$, FD). The observation might explained by the fact that the entire drug in the complex is dissolved 
in the medium, whereas the sediment is made of the free drug only. The stability of the IN- $\beta$ CD complexes decreased as the drug became ionized as the $\mathrm{pH}$ increased due to decrease on the interaction with the hydrophobic cavity of the CD [23].

Table 1

Amount of drug dissolved as complex form in the supernatant

\begin{tabular}{|c|c|c|}
\hline & & Concentration $(\%)^{\mathrm{a}}$ \\
\hline Ibuprofen & IB- $\beta C D$ SD & $26.77 \pm 0.86$ \\
\hline Indomethacin & $\begin{array}{l}\text { IN- } \beta C D \text { SD } \\
\text { IN- } \beta C D \text { FD }\end{array}$ & $\begin{array}{l}0.83 \pm 0.04 \\
0.82 \pm 0.02\end{array}$ \\
\hline
\end{tabular}

a) Mean \pm sd ( $n=3)$

The differences observed in the particles regarding their shape and size $(<250 \mu \mathrm{m})$ for all powders are related to the step of grinding (Fig. 3). The particles of $\beta C D$ present a rectangular shape, while IB particles have shown a well-defined rod shape and IN particles present an irregular shape. The powders which contain free IB and $\beta \mathrm{CD}$ and IB- $\beta \mathrm{CD}$ complex (except IB- $\beta \mathrm{CD}$ PM, Fig. 3) present particles with different shapes, which can be related to the new entity formed (complex) and to the drying methods. The powder produced by PM is made of particles with rod (IB) or rectangular $(\beta \mathrm{CD})$ shapes.

The shape of the particles did not change throughout the process because they were submitted to the process of the mixture, only. On the other hand, the particles produced by AS showed different shapes when compared with the ones produced by PM due to the existence of a new entity (complex), which are irregular in shape produced by the evaporation of the solvent and crystallisation. The few particles found with IB shape correspond to the free IB. The other powders [K, SD (not shown) and FD] have shown particles with irregular shapes corresponding to new entities (complexes).

The small size of these particles can be related to the method of drying and to grinding: powders containing free IN and $\beta \mathrm{CD}$ and IN- $\beta \mathrm{CD}$ complex (except IN- $\beta \mathrm{CD}$ PM, Fig. 3), show the same difference in the shape of the particles. It seems that the method of drying is critical on designing the size and shape of the particles. Due to the fact that the complexation yield is very low (0.82-0.95\%, Table 1$)$, the number of particles produced is not sufficient to provide evidence related to changes of particles of IN- $\beta$ CD in comparison with the raw materials. As anticipated the powders produced by PM have shown particles with the same shapes for IN (irregular) and for $\beta C D$ (rectangular). Particles from powders produced by K or SD (not shown) present smaller sizes but identical shapes to the PM powders. On contrary, powders produced by FD have shown particles with different shapes: a possible explanation might reside on the fact that the complex was not present in a high enough amount for its effect to be significant. Again, the size of the particles is very low and can be related to the method of drying and grinding. 

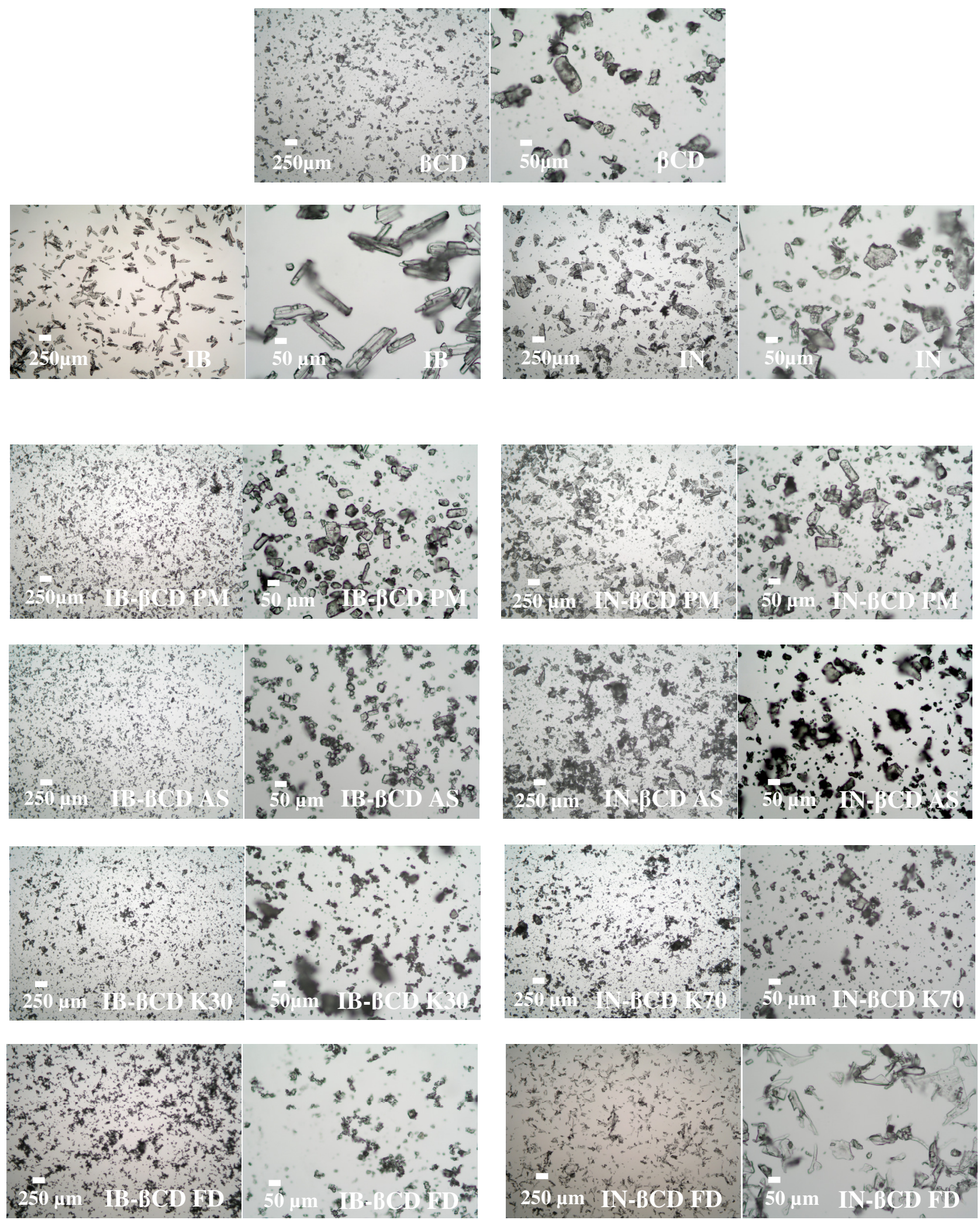

Fig. 3. Photographs of the powders considered in the study: raw materials and products from the physical mixture containing the drug- $\beta \mathrm{CD}$ complex, as observed by optical microscopy. 


\section{3. - Differential scanning calorimetry}

\subsection{1 - Ibuprofen}

The thermograms from the mixtures of powders and raw materials show characteristic thermal behaviours. The comparison between the endothermal transitions of IB, $\beta \mathrm{CD}$, IB- $\beta \mathrm{CD} \mathrm{PM}$ and IB- $\beta \mathrm{CD}$ complexes shows that the powders containing complexes present a temperature shifted- $\beta \mathrm{CD}$ endotherm (Fig. 4A). The characteristic endothermic transition of $\beta \mathrm{CD}$ (Fig. $4 \mathrm{~A}_{\mathrm{b}}$ ) and IB- $\beta \mathrm{CD}$ PM (Fig. $4 \mathrm{~A}_{\mathrm{c}}$ ) ranges between $100-145^{\circ} \mathrm{C}$. The analysis of other endothermic transitions (Fig. $4 \mathrm{~A}_{\mathrm{d}-\mathrm{h}}$ ), regarding the $\beta \mathrm{CD}$, shows shifts on the temperature endotherm to a lower value range $\left(80-120^{\circ} \mathrm{C}\right)$. This change of the endotherm in the latter powders could provide evidence of the complex formation after comparison to $\beta \mathrm{CD}$ and IB- $\beta \mathrm{CD}$ PM endothermic transitions. The shape of the $\beta \mathrm{CD}$ endotherm is changed in all powders containing complexes, although the endothermic transitions for powders produced by kneading $(\mathrm{K})$ were less obvious (Fig. 4 $\mathrm{A}_{\mathrm{e}, \mathrm{f}}$ ). The modification on the shape of the endotherm's line was attributed to the dehydration of the $\beta C D$-ring cavity [14]. This dehydration is more obvious for FD, SD and AS samples than for the $\mathrm{K}$ processes. The endothermic due to the melting of IB are present at $76.3^{\circ} \mathrm{C}$ (Fig. $4 \mathrm{~A}_{\mathrm{a}}$ ). The other values due to the melting endotherm of the IB on the different powders are present at $74.8^{\circ} \mathrm{C}$ for PM (Fig. $4 \mathrm{~A}_{\mathrm{c}}$ ), $74.6^{\circ} \mathrm{C}$ for AS (Fig. $4 \mathrm{~A}_{d}$ ), $74.5^{\circ} \mathrm{C}$ for $\mathrm{K} 30$ (Fig. $4 \mathrm{~A}_{\mathrm{e}}$ ), $75.1^{\circ} \mathrm{C}$ for $\mathrm{K} 70$ (Fig. $4 \mathrm{~A}_{\mathrm{f}}$ ) and $74.9^{\circ} \mathrm{C}$ for FD (Fig. $4 \mathrm{~A}_{\mathrm{h}}$ ). The shape of the IB endotherm in the thermograms for all powders (except IB- $\beta$ CD SD) shows that the free IB is present, i.e., the yield of the inclusion process is not $100 \%$. The absence of an IB endotherm in the powder submitted to $\mathrm{SD}\left(\right.$ Fig. $4 \mathrm{~A}_{\mathrm{g}}$ ) can be due to the temperature conditions used in this method (inlet temperature $125^{\circ} \mathrm{C}$ ). This temperature, higher than the melting temperature of the drug, can be responsible for the disappearance of the free drug present in the powder. The powders containing binary systems present similar values for the melting point.

\subsection{2 - Indomethacin}

For the IN, the comparison on between the thermograms shows a slight temperature shifted- $\beta \mathrm{CD}$ endotherm on the temperature (Fig. 4B). The characteristic endothermic transition of $\beta C D$ (Fig. $4 \mathrm{~B}_{\mathrm{b}}$ ) ranges between $99-145^{\circ} \mathrm{C}$. The analysis of the other endothermic transitions (Fig. $4 \mathrm{~B}_{\mathrm{c}-\mathrm{h}}$ ) concerning $\beta \mathrm{CD}$, shows shifts of the temperature of the endotherm to a lower value range $\left(93-140^{\circ} \mathrm{C}\right)$. This decrease is not very obvious because the yield of the inclusion process for this drug is low and, thus, the percentage of the binary systems for different powders presents very low values. The large amount of free $\beta \mathrm{CD}$ in all different powders led to a similar dehydration behaviour in all of them. The shape of the $\beta \mathrm{CD}$ endotherm in all the powders shows only a small change reflecting a low yield of inclusion. The appearance of an IN endotherm in all thermograms shows that free IN is present in all binary systems. This proves that the yield of inclusion is bellow $100 \%$. The endothermic relative to the melting of IN are present at $160.9^{\circ} \mathrm{C}$ (Fig. $4 \mathrm{~B}_{\mathrm{a}}$ ). The other values corresponding to the melting endothermic transition of IN on the different powders is present at $161.5^{\circ} \mathrm{C}$ for PM (Fig. $4 B_{c}$ ), $162.2^{\circ} \mathrm{C}$ for AS (Fig. $4 B_{d}$ ), $161.1^{\circ} \mathrm{C}$ for $\mathrm{K} 50$ (Fig. $4 B_{e}$ ), $161.0^{\circ} \mathrm{C}$ for $\mathrm{K} 70$ (Fig. $4 \mathrm{~B}_{\mathrm{f}}$ ), $160.7^{\circ} \mathrm{C}$ for $\mathrm{SD}$ (Fig. $4 \mathrm{~B}_{\mathrm{g}}$ ) and $161.7^{\circ} \mathrm{C}$ for $\mathrm{FD}$ (Fig. $4 \mathrm{~B}_{\mathrm{h}}$ ). These values correspond to Form I polymorph for this drug [15]. 


\subsection{3. - Samples washed with an organic solvent}

Fig. 4C and D shows the characteristic thermograms of some powders mixtures after being washed with diethyl ether to remove the free drug. The thermograms of the complexes (Fig. $4 \mathrm{C}_{\mathrm{c}-\mathrm{e}}$ and $4 \mathrm{D}_{\mathrm{c}-\mathrm{e}}$ ) only presented endothermic transitions corresponding to the $\beta \mathrm{CD}$. Furthermore these powders were submitted to ultraviolet scanning showing maxima of absorbance characteristic for each drug identical to the ones observed for the pure drugs. These data provide evidence of inclusion complex formation of the drugs into $\beta \mathrm{CD}$.

A)
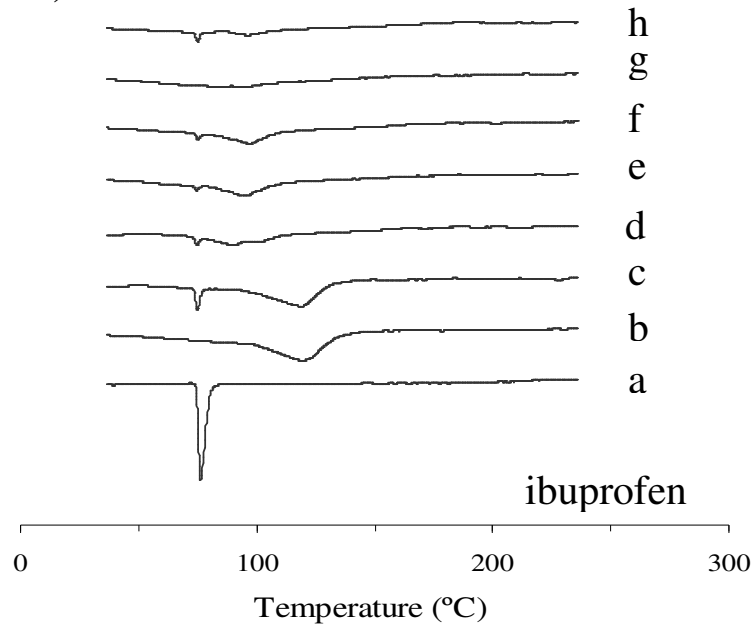

a) IB; b) $\beta C D$; c) IB- $\beta C D$ PM; d) IB- $\beta C D$ AS; e) IB- $\beta C D$ K30; f) IB- $\beta C D$ K70; g) IB- $\beta C D$ SD; h) IB- $\beta C D$ FD

C)
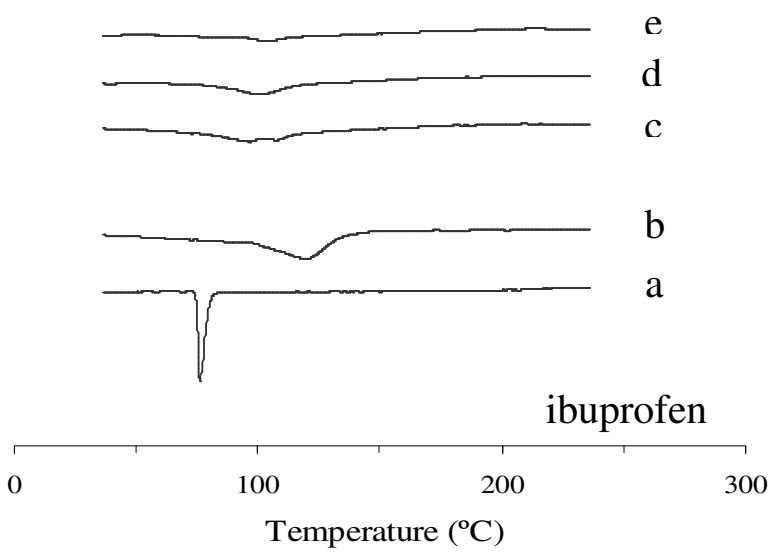

a) IB; b) $\beta C D$; c) IB- $\beta C D$ AS*; d) IB- $\beta C D$ K30*; e) IB- $\beta C D$ FD*
B)

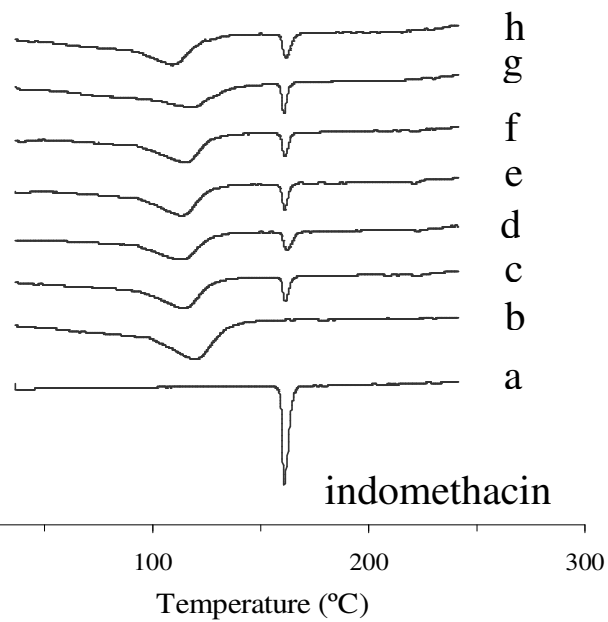

a) IN; b) $\beta C D$; c) IN- $\beta C D$ PM; d) IN- $\beta C D$ AS; e) IN- $\beta C D$ K50; f) IN- $\beta C D$ K70; g) IN- $\beta C D$ SD; h) IN- $\beta C D$ FD

D)
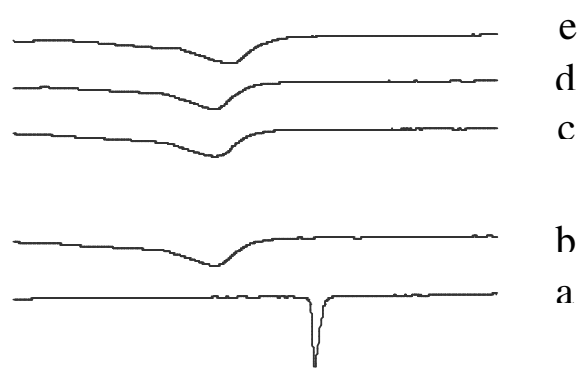

indomethacin

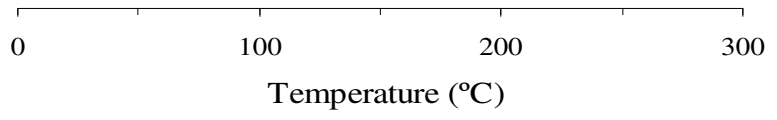

a) IN; b) $\beta C D$; c) IN- $\beta C D$ AS*; d) IN- $\beta C D$ K70*; e) IN- $\beta C D$ FD*

Fig. 4. Thermograms of $\mathrm{A})$ and $\mathrm{B}$ ) drug, $\beta \mathrm{CD}$, drug- $\beta \mathrm{CD}$ physical mixture and drug$\beta \mathrm{CD}$ complexes; C) and D) drug, $\beta \mathrm{CD}$ and drug- $\beta \mathrm{CD}$ complexes washed with diethyl ether. 


\section{4. - FT-Infrared spectroscopy}

Samples of raw materials and powders were analysed by FT-Infrared spectroscopy (FT-IR). The spectral region from 4000 to $3000 \mathrm{~cm}^{-1}$ is difficult to analyse for $\beta \mathrm{CD}$ and its complexes due to primary and secondary 'OH' groups of $\beta \mathrm{CD}$ and water molecules of crystallization. The symmetrical bending band of water in $\beta C D$ hydrate appears at $1644.7 \mathrm{~cm}^{-1}\left(1650-1630 \mathrm{~cm}^{-1}[14,24,25]\right)$ (Fig. 5a). The intensity of this band was used as an internal reference for the water content in the $\beta C D$ samples [22]. In all spectra, this band presented a small shift due to changes in the hydrated bonds within $\beta \mathrm{CD}[14]$.

\subsection{1. - Ibuprofen}

The spectrum of the IB shows the presence of a stretching band at $1721.3 \mathrm{~cm}^{-1}$ correspondent to the carbonyl group (' $\mathrm{C}=\mathrm{O}$ ', from a carboxylic acid group). The ' $\mathrm{C}=\mathrm{O}$ ' stretching bands of acidic groups are considerably more intense than ketonic ' $\mathrm{C}=\mathrm{O}$ ' stretching bands. Two bands arising from ' $\mathrm{C}=\mathrm{O}$ ' stretching and ' $\mathrm{OH}$ ' bending appear in the spectra of carboxylic acids 1422.7 and 1320.0 or $1225.0 \mathrm{~cm}^{-1}(1440-1395$ and 1320 $1210 \mathrm{~cm}^{-1}$ [25]), respectively (Fig. 5a $_{1}$ [25]. The analysis of the spectra from powders K30*, and FD* (*denotes washed samples) (Fig. $5 \mathrm{c}_{1}$ and $\mathrm{c}_{2}$ ) shows the acid carbonyl stretching band shifted to a higher frequency $\left(1729.6 \mathrm{~cm}^{-1}\right)$. This shift in wavelength might be due to the breakdown of intermolecular hydrogen bonding of the crystals, strengthened by ionic resonance, associated with the IB dimmers and the establishment of weaker forces. It follows that, the formation of a monomeric dispersion of the drug, as a consequence of the interaction with $\beta \mathrm{CD}$ could result in the inclusion of the drug monomer into the hydrophobic cavity of the CD. In the spectra of IB- $\beta$ CD PM (Fig $\left.5 b_{1}\right)$ the carbonyl stretching band appeared at the same wavenumber (1721.3 $\mathrm{cm}^{-1}$ ) of the pure drug IB (Fig.5 $\left.\mathrm{a}_{2}\right)$ [14, 25-31]. Other spectra (not shown) presented shifts in this peak which corresponds to the carbonyl group $\left(1737.4 \mathrm{~cm}^{-1}\right.$ for IB- $\beta$ CD AS, $1742.9 \mathrm{~cm}^{-1}$ for IB- $\beta$ CD SD, $1743.2 \mathrm{~cm}^{-1}$ for IB- $\beta$ CD FD, $1736.0 \mathrm{~cm}^{-1}$ for IB- $\beta$ CD $\mathrm{AS}^{*}$ higher frequency and $1708.5 \mathrm{~cm}^{-1}$ for IB- $\beta \mathrm{CD} \mathrm{K} 30$ and $1709.1 \mathrm{~cm}^{-1}$ for IB- $\beta \mathrm{CD}$ K70 lower frequency). The shift of a band on the corresponding carbonyl group proved the presence of the solid complex formation suggested this group was not fully included within the CD cavity.

Several authors $[26,28,32]$ have shown that by molecular modelling it is possible to predict the conformation of the complex of the IB into the $\beta \mathrm{CD}$ cavity with a slight inclination. The portions of the drug molecule inside the $\beta \mathrm{CD}$ cavity are the isopropyl group and a part of the aromatic ring.

\subsection{2. - Indomethacin}

The spectrum of the IN has shown the presence of two bands around 1721.3 and $1689.4 \mathrm{~cm}^{-1}$ corresponding to the carbonyl group (both ketone and carboxylic acid contributions). The fact this group shows a strong stretching absorption band in the region of $1870-1540 \mathrm{~cm}^{-1}$ is due to a constant position, high intensity and freedom from interfering bands, which make it useful to recognize in the IR spectra [25, 33]. The range between $900-600 \mathrm{~cm}^{-1}$ presents more intense and informative bands in the spectra of aromatic compounds [15, 25] (Fig. 5a $\mathrm{a}_{3}$ ). An examination of all spectra obtained from powders with binary systems produced with IN, not submitted to washing process with the organic solvent (not shown), revealed two small but distinct bands at 1721.3 and 
near $1689 \mathrm{~cm}^{-1}$ (carbonyl groups), which prove the existence of the free drug in the powder $\left(1685.7 \mathrm{~cm}^{-1}\right.$ for IN- $\beta$ CD AS, $1685.7 \mathrm{~cm}^{-1}$ for IN- $\beta$ CD K50, $1689.4 \mathrm{~cm}^{-1}$ for IN$\beta$ CD K70, $1685.7 \mathrm{~cm}^{-1}$ for IN- $\beta$ CD SD and $1685.7 \mathrm{~cm}^{-1}$ for IN- $\beta$ CD FD) [25, 31]. These bands occur in IN- $\beta$ CD PM (Fig. $5 b_{2}$ ). Moreover, the spectrum showed small peaks around $1312 \mathrm{~cm}^{-1}$ which were attributed to 'C-H' bending, 'C-O' stretching and 'O-H' deformation absorbances within IN (i.e., groups not fully included within the $\beta \mathrm{CD}$ ) $[14$, 26-29]. The other bands in the IR spectra from the complexes were similar to pure $\beta C D$ and dissimilar to the corresponding pure drug (Fig. $5 c_{3}$ and $c_{4}$ ). The samples, after being washed with diethyl ether, have presented spectra without bands due to carbonyl groups but showing the peaks at $1634.1 \mathrm{~cm}^{-1}$ for IN- $\beta$ CD AS* (not shown), $1640.9 \mathrm{~cm}^{-1}$ (IN$\beta \mathrm{CD} \mathrm{K} 30)^{*}$ and $1634.1 \mathrm{~cm}^{-1}$ (IN- $\beta$ CD FD*) corresponding to a change in the hydrated bonds within $\beta \mathrm{CD}$. The disappearance of the bands due to carbonyl groups of IN on the complex spectra (washed samples) about $1689.0 \mathrm{~cm}^{-1}$ suggests the inclusion of the two carbonyl groups into the CD cavity (Fig. $5 \mathrm{c}_{3}$ and $\mathrm{c}_{4}$ ) [14]. 


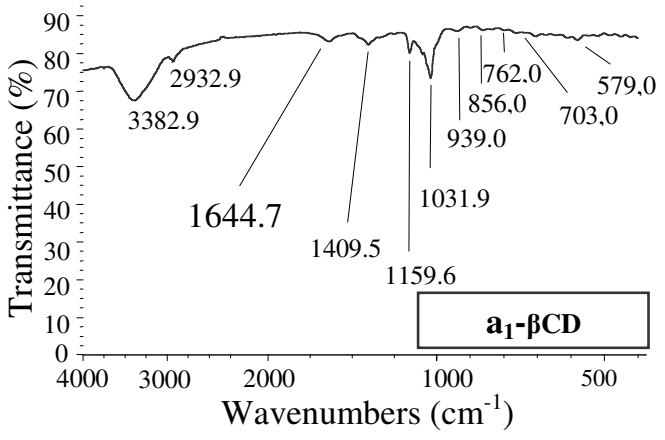

A)

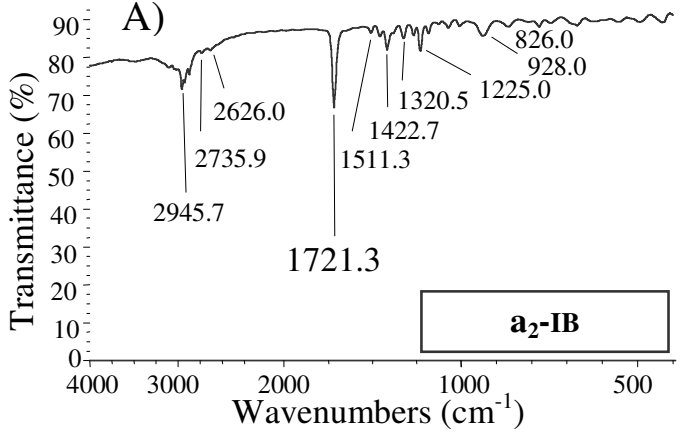

A)

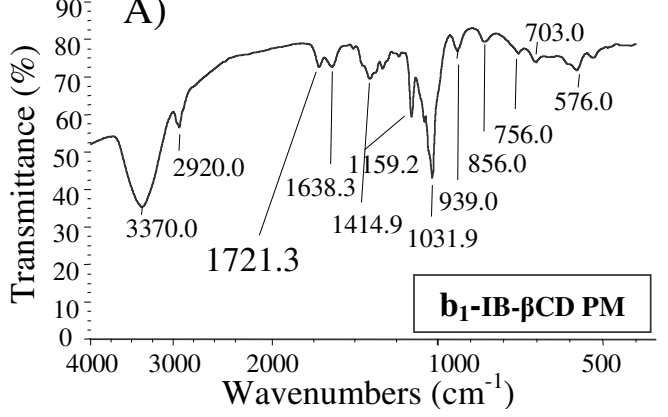

A)

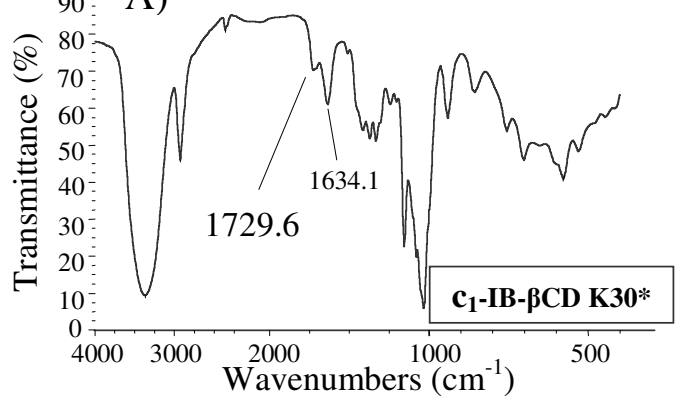

A)

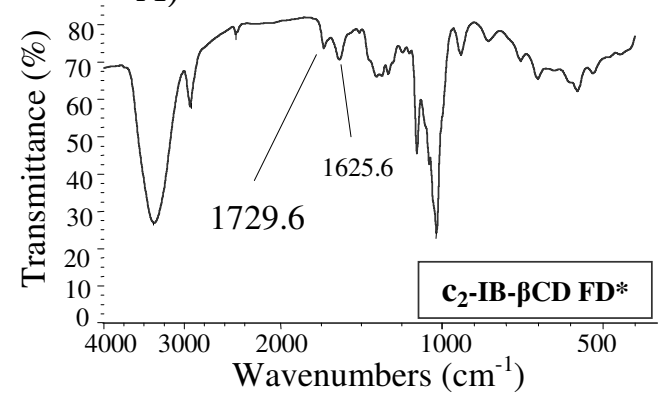

B)

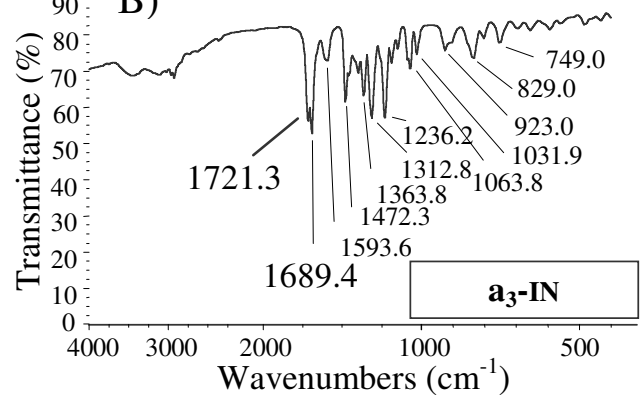

B)

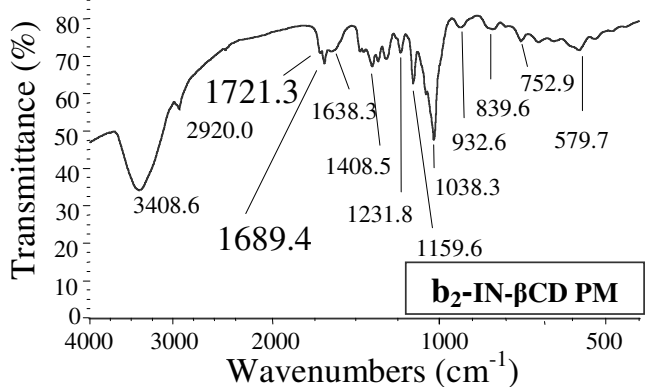

B)

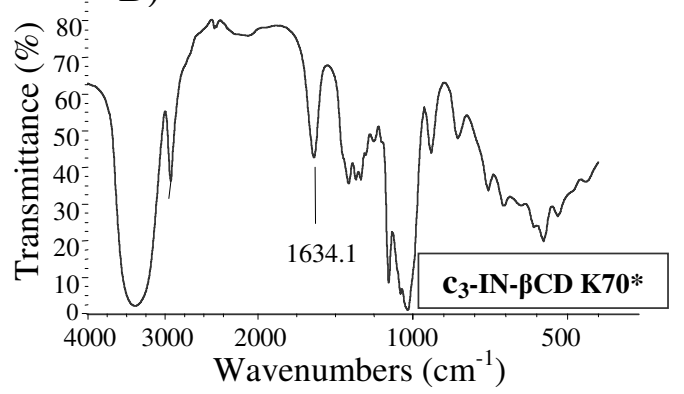

B)

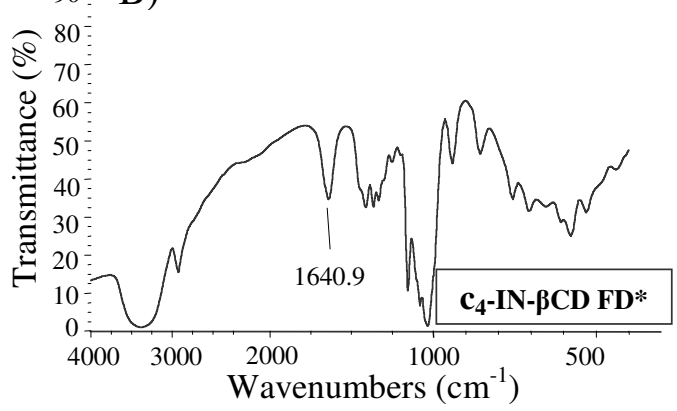

Fig. 5. Infrared spectrum of the drug- $\beta C D$ : A) ibuprofen and B) indomethacin a) raw materials $\left(\mathrm{a}_{1}, \mathrm{a}_{2}\right.$ and $\left.\mathrm{a}_{3}\right)$; (b) physical mixture $\left(\mathrm{b}_{1}\right.$ and $\left.\mathrm{b}_{2}\right)$; (c) complexes after washing with diethyl ether $\left(c_{1}, c_{2}, c_{3}\right.$ and $\left.c_{4}\right)$. 


\section{5. - Nuclear magnetic resonance}

NMR proton spectroscopy has been a frequently used spectroscopic analytical tool to study the inclusion of guest molecules into a host $[5,10,21,34]$. Here we have addressed the possible inclusion/complexation of the two drugs considered (IB and IN) in a host macrocycle $(\beta \mathrm{CD})$ with simple $1 \mathrm{D}$ proton spectroscopy, combined with other complementary characterisation techniques. It was possible to record four proton spectra of aqueous saturated solutions (in $\mathrm{D}_{2} \mathrm{O}$ ) of IB- $\beta \mathrm{CD}$ and $\mathrm{IN}-\beta \mathrm{CD}$ powders, submitted and not submitted to a previous washing procedure. These spectra were compared to the spectrum of a $\beta \mathrm{CD}$ solution in order to identify line shifts that could provide evidence for a complexation phenomena, and to study the possible effect of the washing procedure on both powders [35]. It is well known that $\beta \mathrm{CD}$ has the topology of a hollow cone shape, with the $\mathrm{H}(3)$ and $\mathrm{H}(5)$ being inner protons. Many other inclusion studies point to a spatial arrangement where the hydrophobic guest molecules penetrate in the toroidal cavity, forming inclusion complexes that mainly affect the inner protons of the macrocycle. Therefore, our study should focus in first place on the behaviour of the $\beta \mathrm{CD}$ protons in the $\mathrm{H}(3)$ and $\mathrm{H}(5)$ chemical shift range. Comparing the $\beta \mathrm{CD}$ solution spectrum and the spectra of the non-washed powders of IB- $\beta$ CD and IN- $\beta$ CD (Fig. 6A), a significantly induced chemical shift (up-field) for the inner protons $\mathrm{H}(5)$ and $\mathrm{H}(3)$ in both samples is easily recognized, this effect being stronger in the IB- $\beta \mathrm{CD}$ powder mainly for $\mathrm{H}(5)$. The formation of a complex by inclusion is clearly put in evidence by these spectral features which may be the result of either a higher inner proton $\mathrm{H}(5)$ shielding in the $\beta \mathrm{CD}$ cavity or a larger stability at the equilibrium between complexes and free species (or both) [26, 28].

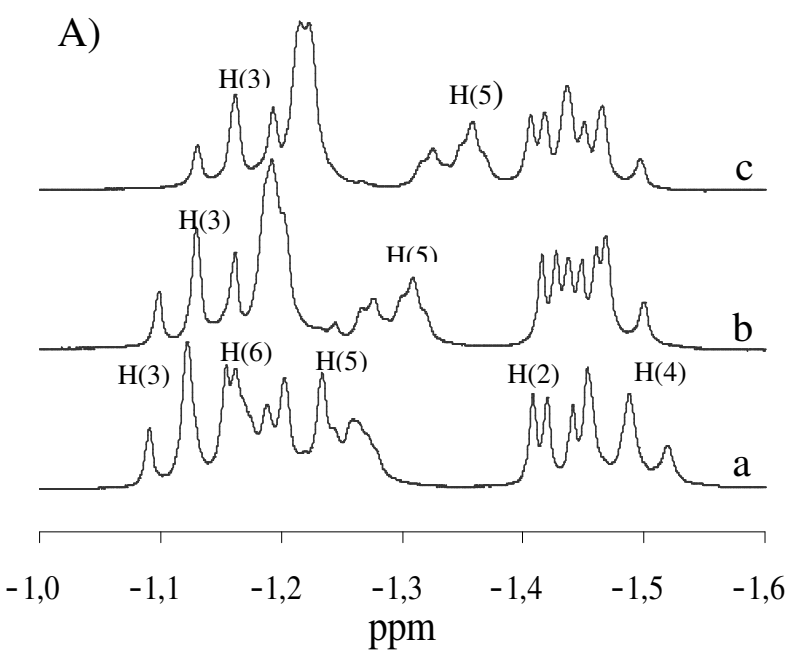

a) $\beta C D$; b) IN- $\beta$ CD K70; c) IB- $\beta$ CD FD

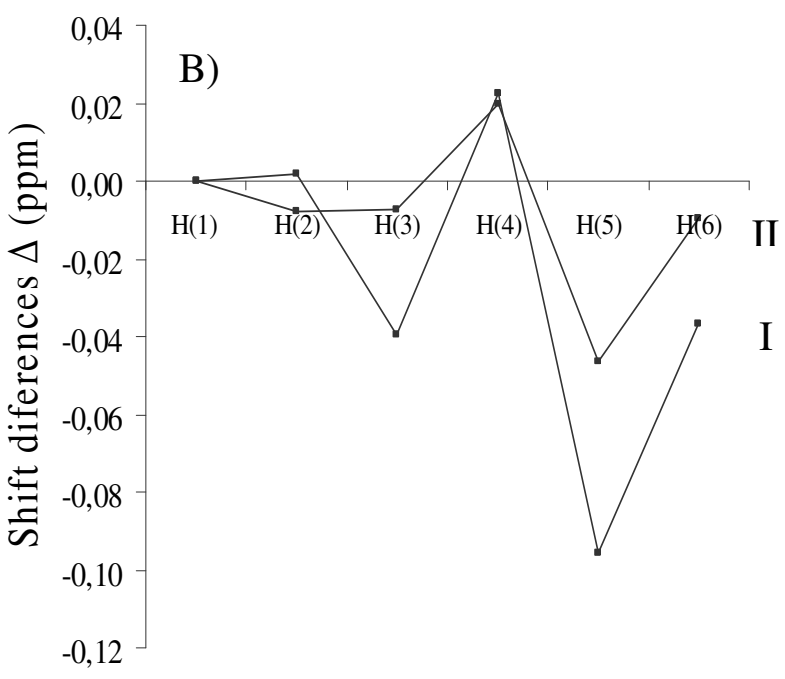

$\mathrm{I}-\Delta_{\mathrm{ba}}^{\mathrm{i}}=\delta_{\mathrm{b}}^{\mathrm{i}}-\delta_{\mathrm{a}}^{\mathrm{i}} ; \mathrm{II}-\Delta_{\mathrm{ca}}^{\mathrm{i}}=\delta_{\mathrm{c}}^{\mathrm{i}}-\delta_{\mathrm{a}}^{\mathrm{i}}$

Fig. 6. Chemical shifts of protons in solution (reference $\mathrm{H}(1)$ at $0 \mathrm{ppm}$ ) produced by NMR:

A) pure compound (a) and of the non-washed mixtures (b and c);

B) chemical shift diferences of each $\beta \mathrm{CD}$ proton $\mathrm{H}(\mathrm{i}),(\mathrm{i}=1, \ldots, 6)$ between the shifts of the pure $\beta \mathrm{CD}$ (a) and the shifts in the IB- $\beta \mathrm{CD}$ (b) and IN- $\beta \mathrm{CD}$ (c) mixtures (nonwashed). 
Table 2 shows the chemical shifts of the central point of the $\beta \mathrm{CD}$ proton multiplets, in simple solution and in the presence of complex forming agents, in nonwashed powders, with reference to the $\mathrm{H}(1)$ proton, as well as the shift differences between equivalent spectral points of the $\beta \mathrm{CD}$ solution and each one of the powder solutions: IB- $\beta$ CD and IN- $\beta$ CD. These results are shown in Fig. $6 \mathrm{~B}$, in which the larger shift for the $\mathrm{H}(3)$ and $\mathrm{H}(5)$ protons and the stronger shift effect for the IB- $\beta$ CD are immediately quantified which may be the result of either a higher inner proton $\mathrm{H}(5)$ shielding in the $\beta \mathrm{CD}$ cavity or a larger stability in the equilibrium between complexes and free species (or both) [26, 28].

Applying the same NMR proton analysis to the washed IB- $\beta$ CD and IN- $\beta$ CD powders, the same shift effects are observed in the latter, but there are no relevant modifications with respect to the $\mathrm{IN}-\beta \mathrm{CD}$ system spectra. We have to draw the conclusion that the IN, which is present at a very low concentration in the solution due its low solubility, was substantially removed from the host $\beta \mathrm{CD}$ molecule by the washing operation, in opposition to the IB- $\beta$ CD powder.

Table 2

Chemical shifts of the $\beta \mathrm{CD}$ protons in the NMR spectra of the compound and of its mixtures with IB and IN

\begin{tabular}{lcccccc}
\hline \multicolumn{1}{c}{$\delta(\mathrm{ppm})$} & $\mathrm{H}(1)$ & $\mathrm{H}(2)$ & $\mathrm{H}(3)$ & $\mathrm{H}(4)$ & $\mathrm{H}(5)$ & $\mathrm{H}(6)$ \\
& $\mathrm{d}$ & $\mathrm{dd}$ & $\mathrm{t}$ & $\mathrm{t}$ & $\mathrm{m}$ & $\mathrm{m}$ \\
\hline$\beta \mathrm{CD}\left(\delta_{\mathrm{A}}^{\mathrm{i}}\right)$ & 0.000 & -1.431 & -1.122 & -1.488 & -1.246 & -1.182 \\
$\mathrm{IB}-\beta \mathrm{CD}\left(\delta_{\mathrm{B}}^{\mathrm{i}}\right)$ & 0.000 & -1.429 & -1.162 & -1.466 & -1.342 & -1.219 \\
$\mathrm{IN}-\beta \mathrm{CD}\left(\delta_{\mathrm{C}}^{\mathrm{i}}\right)$ & 0.000 & -1.438 & -1.130 & -1.468 & -1.293 & -1.192 \\
\hline$\Delta^{\mathrm{i}}{ }_{\mathrm{BA}}=\left(\delta_{\mathrm{B}^{-}}^{\mathrm{i}} \delta_{\mathrm{A}}^{\mathrm{i}}\right)$ & 0.000 & 0.002 & -0.040 & 0.023 & -0.096 & -0.037 \\
$\Delta_{\mathrm{CA}}^{\mathrm{i}}=\left(\delta_{\mathrm{C}^{-}}^{\mathrm{i}}{ }^{\mathrm{i}}{ }_{\mathrm{A}}\right)$ & 0.000 & -0.008 & -0.007 & 0.020 & -0.047 & -0.010 \\
\hline
\end{tabular}

Chemical shifts of the $\mathrm{H}(\mathrm{i})$ protons $(\mathrm{i}=1, \ldots 6)$ of $\beta \mathrm{CD}\left(\delta_{\mathrm{A}}{ }^{\mathrm{i}}\right)$ and IB- $\beta \mathrm{CD}\left(\delta_{\mathrm{B}}{ }^{\mathrm{i}}\right)$ and in IN- $\beta \mathrm{CD}\left(\delta_{\mathrm{C}}{ }^{\mathrm{i}}\right)$ non-washed mixtures in solution [ppm values with $\mathrm{H}(1)$ as reference]. $\Delta_{\mathrm{BA}}^{\mathrm{i}}$ (in the IB- $\beta \mathrm{CD}$ mixture) and $\Delta_{\mathrm{CA}}^{\mathrm{i}}$ (in the IN- $\beta \mathrm{CD}$ mixture). These values are represented in the Fig. 6B.

\section{6. - X-ray diffractrometry}

Fig. 7A presents the X-ray scattering pattern obtained from samples containing different powders. By comparing the patterns (d) and (e) from the washed powders with the patterns from $\beta \mathrm{CD}$ (a) and IB (b) one can observe that the scattering peaks found in patterns (d) and (e) are very similar to each other when registered but not to the scattering peaks registered in pattern (a) or (b). This is an indication that a new entity is being observed in patterns (d) and (e) relative to patterns (a) and (b) and thus corresponds to the inclusion complex. The absence of peaks from either $\beta \mathrm{CD}$ or IB on patterns (d) and (e) means that the amounts of these substances (if exist) are beyond detection and this arises because free IB was removed through washing and $\beta C D$ remains in a too small fraction for detection due to a high inclusion yield. By observing the scattering pattern from the non washed powder complex (IB- $\beta$ CD) one finds all the peaks found in patterns (d) and (e) correspond to the inclusion complex and extra peaks 
that where registered along with peaks from IB (pattern b) corresponding to the free IB. The absence of peaks from non complexed $\beta \mathrm{CD}$ is caused by a low percentage of this component in the powder as discussed above [31, 36, 37]. Fig. 7B presents X-ray scattering patterns obtained from samples containing different powders. By comparing the pattern (c) from the non washed powder with the patterns from $\beta C D$ (a) and IN (b) one can observe that the scattering peaks found in pattern (c) are all in registered the scattering peaks in pattern (a) or pattern (b). No new scattering peaks are present in pattern (c) relative to both patterns (a) and (b) indicating that the amount of complex is beyond detection in this powder. Pattern (d) from the washed powder shows scattering peaks in registered with the pattern (a) without any contribution from pattern (b) indicating that once more the amount IN- $\beta$ CD complex is beyond detection, and the free IN was efficiently removed with the washing process [20, 31, 38]. The lack of evidence for the presence of complex in both samples (c) and (d) may have its origin on the very low yield of the inclusion process for IN on $\beta \mathrm{CD}$ with an estimated yield of 0.82 to $0.95 \%$.

A)

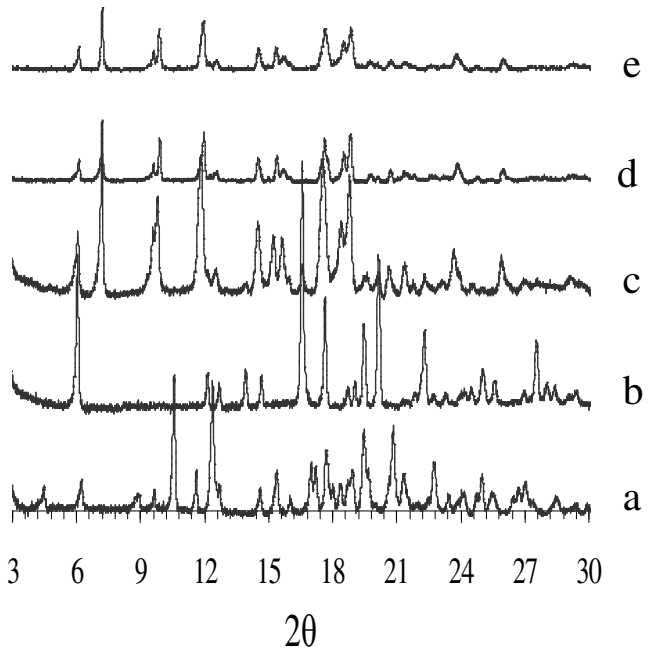

a) $\beta C D$; b) IB; c) IB- $\beta C D$ FD; d) IB- $\beta C D$ FD*; e) IB- $\beta C D$ K70*
B)

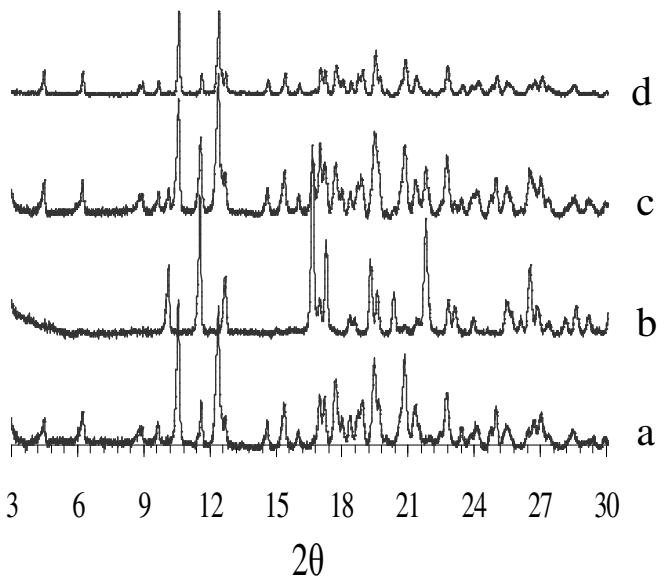

a) $\beta C D$; b) IN; c) IN- $\beta C D$ K70; d) IB- $\beta C D$ K70*

Fig. 7. X-ray scattering patterns obtained from samples containing powders: A) ibuprofen and B) indomethacin.

3.7. - Assay

The contents $(\%)$ of each drug in all the binary systems powders are showed in the Table 3 (IB and IN). All values, except IB- $\beta$ CD SD value are into the interval of $100 \pm 5 \%$. The low value of the IB- $\beta$ CD SD has been addressed previously, when the results from the calorimetry studies were discussed. Table 4 (IB and IN) presents the amounts $(\%)$ of free drug and drug as a complex form from each powder dissolved at different values of $\mathrm{pH}$. 
Table 3

Amount of total drug in each powder

\begin{tabular}{|c|c|c|}
\hline & & Concentration $(\%)^{\mathrm{a}}$ \\
\hline Ibuprofen & $\begin{array}{c}\text { IB- } \beta \text { CD PM } \\
\text { IB- } \beta \text { CD AS } \\
\text { IB- } \beta \text { CD K30 } \\
\text { IB- } \beta \text { CD K70 } \\
\text { IB- } \beta \text { CD SD } \\
\text { IB- } \beta \text { CD FD }\end{array}$ & $\begin{array}{c}96.35 \pm 0.18 \\
96.00 \pm 0.26 \\
97.70 \pm 0.09 \\
99.65 \pm 0,33 \\
76.97 \pm 0.00 \\
102.42 \pm 0.09\end{array}$ \\
\hline Indomenthacin & $\begin{array}{c}\mathrm{IN}-\beta C D \text { PM } \\
\text { IN- } \beta \text { CD AS } \\
\text { IN- } \beta \text { CD K50 } \\
\text { IN- } \beta \text { CD K70 } \\
\text { IN- } \beta \text { CD SD } \\
\text { IN- } \beta \text { CD FD }\end{array}$ & $\begin{array}{l}97.23 \pm 0.11 \\
99.15 \pm 0.12 \\
96.02 \pm 0.00 \\
97.03 \pm 0.20 \\
96.05 \pm 0.12 \\
99.92 \pm 0.49\end{array}$ \\
\hline
\end{tabular}

a) mean \pm sd $(n=3)$

At $\mathrm{pH} 2$ the amount of IB dissolved as a complex form was practically the same for all powders, except IN- $\beta$ CD PM. At these levels, the amount of drug dissolved from IB- $\beta$ CD PM is smaller because this powder does not contain IB in the complex (Table 4). This content is higher than free IB due to the fact that during the preparation of the solution some complex was formed. At $\mathrm{pH} 5$ an increase of the amount of drug dissolved occurred, because a part of the free drug was dissolved at this $\mathrm{pH}$. At $\mathrm{pH} 7$, all powders present the largest values because at this $\mathrm{pH}$ the drug dissolved results from the free and the complex drug. At this $\mathrm{pH}$, the IB presented a solubility of $1.0 \mathrm{mg} / \mathrm{ml}$ at $20^{\circ} \mathrm{C}$ [12]. For the different $\mathrm{pH}$ values, the amount of IB-CD SD did not increase maybe due to the previously explained in section 3.3.1.

At $\mathrm{pH} 2$, the amount of IN dissolved as a complex form was practically the same for all powders, except IN- $\beta$ CD PM. The amount of drug dissolved from IN- $\beta$ CD PM is lower because this powder did not contain IN as a complex. This content is higher than free IN due to the fact that during the preparation of the solution some complex might

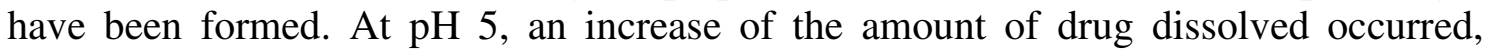
because a part of the free drug was dissolved at this $\mathrm{pH}$ [15]. At $\mathrm{pH} 7$, all powders presented the largest values of the drug that dissolved because for this value of $\mathrm{pH}$, part of the drug dissolves as a non-complexed salt and drug as a complex form. At this $\mathrm{pH}$ the IN, Form I, presents a solubility of $54 \mathrm{mg} / 100 \mathrm{ml}$ at $25^{\circ} \mathrm{C}$ [15]. 
Table 4

Amount of the drug dissolved at different $\mathrm{pHs}$

\begin{tabular}{|c|c|c|c|c|}
\hline & & \multicolumn{3}{|c|}{ Concentration $(\%)^{\mathrm{a}}$} \\
\hline \multirow{8}{*}{ Ibuprofen } & & $\mathrm{pH} 2$ & pH 5 & $\mathrm{pH} 7$ \\
\hline & $\mathrm{IB}-\beta \mathrm{CD}$ PM & $43.79 \pm 0.69$ & $46.45 \pm 1.16$ & $84.56 \pm 0.66$ \\
\hline & $\mathrm{IB}-\beta \mathrm{CD}$ AS & $75.71 \pm 1.62$ & $79.57 \pm 1.03$ & $93.01 \pm 1.46$ \\
\hline & IB- $\beta$ CD K30 & $83.72 \pm 0.71$ & & \\
\hline & IB- $\beta$ CD K70 & $82.25 \pm 1.58$ & & \\
\hline & IB- $\beta$ CD SD & $78.95 \pm 1.32$ & $77.99 \pm 1.94$ & $71.19 \pm 1.33$ \\
\hline & IB- $\beta \mathrm{CD}$ FD & $78.57 \pm 0.83$ & $85.91 \pm 0.31$ & $97.02 \pm 0.70$ \\
\hline & IB & $18.70 \pm 0.99$ & & \\
\hline \multirow{7}{*}{ Indomethacin } & $\mathrm{IN}-\beta \mathrm{CD}$ PM & $0.48 \pm 0.09$ & $3.59 \pm 0.67$ & $24.84 \pm 0.32$ \\
\hline & $\mathrm{IN}-\beta \mathrm{CD}$ AS & $0.82 \pm 0.10$ & $4.32 \pm 0.20$ & $24.36 \pm 0.29$ \\
\hline & $\mathrm{IN}-\beta \mathrm{CD}$ K50 & $0.91 \pm 0.16$ & & \\
\hline & $\mathrm{IN}-\beta \mathrm{CD}$ K70 & $0.94 \pm 0.18$ & & \\
\hline & IN- $\beta$ CD SD & $1.09 \pm 0.18$ & $3.76 \pm 0.15$ & $29.59 \pm 0.35$ \\
\hline & $\mathrm{IN}-\beta \mathrm{CD}$ FD & $0.95 \pm 0.15$ & $4.06 \pm 0.79$ & $20.77 \pm 1.41$ \\
\hline & IN & $0.16 \pm 0.14$ & & \\
\hline
\end{tabular}

a) mean \pm sd $(n=3)$

\section{Conclusions}

The results obtained from the different preparations have shown the presence of a complex in each powder. Water is necessary to promote the inclusion but its amount is not so important if the intrinsic solubility of the drug is not modified. The results of the formation of the inclusion complex obtained from the different methods related to interactions in an aqueous solution and in the solid state suggest a mechanism of complexation by inclusion of the drug in the cavity of the $\beta \mathrm{CD}$, process that is similar for all the techniques and drugs considered. The kneading process showed the same yield as the other methods tested with several advantages, namely more economic and less time consumption to obtain the complex. The different analytical methods considered (DSC, IR, X-Ray and NMR) in combination provided evidence of the complex formation, particularly with NMR making clear a neat complexation effect in $\mathrm{H}(3)$ and $\mathrm{H}(5)$. This effect is much stronger in the IB- $\beta$ CD powder than in the IN- $\beta C D$ one, and justifies the different yields of inclusion into a complex for the two drugs. The IB X-ray shows that the process of inclusion provides new patterns to the molecular structures. In the IN X-ray the spectra produced before and after the washing process with diethyl ether were the same, due to a low inclusion yield. Crystals were present in all complexes formed although the ones produced by FD seem to have a higher fraction of amorphous material. Different methods produced powders with different moisture contents where the FD and SD powders were the ones with less water. 


\section{References}

[1] M. Charoenchaitrakool, F. Dehghani, N.R. Foster, Utilization of supercritical carbon dioxide for complex formation of ibuprofen and methyl- $\beta$-cyclodextrin, Int. J. Pharm. 239 (2002) 103-112.

[2] T. Loftsson, D. Hreinsdóttir, M. Másson, Evaluation of cyclodextrin solubilization of drugs, Int. J. Pharm. 302 (2005) 18-28.

[3] T. Loftsson, D. Duchêne, Cyclodextrins and their pharmaceutical applications, Int. J. Pharm. 329 (2007) 1-11.

[4] B. Pose-Vilarnovo, C. Rodriguez-Tenreiro, J.F Santos, J. Vásquez-Doval, A. Concheiro, C. Alvarez-Lorenzo, J. Torres-Labandeira, Modulating drug release with cyclodextrins in hydroxypropyl methycellulose gels and tablets, J. Control. Release 94 (2004) 351-363.

[5] M.T. Faucci, F. Melani, P. Mura, ${ }^{1} \mathrm{H}$ NMR and molecular modeling techniques for the investigation of the inclusion complex of econazole with $\alpha$-cyclodextrin in presence of malic acid, J. Pharm. Biomed. Anal. 23 (2000) 25-31.

[6] T. Loftsson, M. Másson, M.E. Brewster, Self-association of cyclodextrins and cyclodextrins complexes, J. Pharm. Sci. 93 (2004) 1091-1099.

[7] T. Loftsson, Í.B. Össurardóttir, M. Duan, N. Zhao, T. Thorsteinsson, M. Másson, Cyclodextrin solubilization of the antibacterial agents triclosan and triclocarban: effect of ionization and polymers, J. Incl. Phenom. Macroc. Chem. 52 (2005) 109-117.

[8] M. Duan, N. Zhao, Í.B. Össurardóttir, T. Thorsteinsson, T. Loftsson, Cyclodextrin solubilization of the antibacterial agents triclosan and triclocarban: formation of aggregates and higher-order complexes, Int. J. Pharm. 297 (2005) 213-222.

[9] T. Loftsson, D. Hreinsdóttir, M. Másson, The complexation efficiency, J Incl. Phenom. Macrocycl. Chem. 57 (2007) 545-552.

[10] D.Z. Sun, L. Li, X.M. Qiu, F. Liu, B-L. Yin, Isothermal titration calorimetry and ${ }^{1}$ H NMR studies on host-guest interaction of paeonol and two of its isomers with $\beta$-cyclodextrin, Int. J. Pharm. 316 (2006) 7-13.

[11] T. van Hees, G. Piel, B. Evrard, X. Otte, L. Thunus, L. Delattre, Application of supercritical carbon dioxide for the preparation of a piroxicam- $\beta$-cyclodextrin inclusion compound, Pharm. Res. 16 (1999) 1864-1870.

[12] J.D. Higgins, T.P. Gilmor, S.A. Martellucci, R.D. Bruce, H.G. Brittain, Ibuprofen, in: Analytical Profiles of Drug Substances, 27, (2001) pp. 265-300.

[13] J. Nerurkar, J.W. Beach, M.O. Park, H.W. Jun, Solubility of ( \pm )-ibuprofen and S (+)-ibuprofen in the presence of cosolvents and cyclodextrins, Pharm. Dev. Technol. 10 (2005) 413-421.

[14] S. Jambhekar, R. Casella, T. Maher, The physicochemical characteristics and bioavailability of indomethacin from $\beta$-cyclodextrin, hydroxyethyl- $\beta$-cyclodextrin and hydroxypropyl- $\beta$ cyclodextrin complexes, Int. J. Pharm. 270 (2004) 149-166.

[15] M. O'Brien, J. McCauley, E. Cohen, Indomethacin, in: Florey, K. (Ed.), Analytical Profiles of Drug Substances. San Diego, Academic Press Inc., 13, 1984, pp..211-238.

[16] C.-Y. Wu, L.Z. Benet, Predicting drug disposition via application of BCS: transport/absorption/ elimination interplay and development of a Biopharmaceutics Drug Disposition Classification System, Pharm. Res. 22 (2005) 11-23.

[17] L.A. Miller, R.L. Carrier, I. Ahmed, Pratical considerations in development of solid dosage forms that contain cyclodextrin, J. Pharm. Sci. 96 (2007) 1691-1707.

[18] T. Higuchi, K.A. Connors, Phase solubility technique, Adv. Anal. Chem. Instrum. 4 (1965) 117212.

[19] W.L. Lu, Q. Zhang, L. Zheng, H. Wang, R.Y. Li, L.F. Zhang, W.B. Shen, X.D. Tu, Antipyretic, analgesic and anti-inflammatory activities of ketoprofen $\beta$-cyclodextrin inclusion complex in animals, Biol. Pharm. Bull. 27 (2004) 1515-1520.

[20] M. Wulff, M. Aldén, Solid state studies of drug-cyclodextrin inclusion complexes in PEG 6000 prepared by a new method, Eur. J. Pharm.Sci. 8 (1999) 269-281.

[21] D. Salvatierra, C. Jaime, A. Virgil, F. Sánchez-Ferrando, Determination of the Inclusion Geometry for the $\beta$-Cyclodextrin/Benzoic Acid Complex by NMR Molecular Modeling, J. Org. Chem. 61 (1996) 9578-9581.

[22] European Pharmacopeia 6.0, $6^{\text {th }}$ ed., vol. 1, edqm, Council of Europe, European Department for the quality Medicine, Brussels, 2008, pp. 508-511.

[23] M.K. Ghorab, M.C. Adeyeye, Enhanced bioavailability of process-induced fast-dissolving ibuprofen cogranulated with $\beta$-cyclodextrin, J. Pharm. Sci. 92 (2003) 1690-1697.

[24] J.M. Gavira, A. Hernanz, I. Bratu, Dehydartion of $\beta$-cyclodextrin, An IR $v(\mathrm{OH})$ band profile analysis, Vib. Spectrosc. 32 (2003) 137-146. 
[25] R.M. Silverstein, G.C. Bassler, T.C. Morrill, Infrared spectrometry, in: Spectrometric Identification of Organic Compounds, $5^{\text {th }}$ ed., John Wiley \&Sons, Inc, New York, 1991, pp. 91164.

[26] M.K. Ghorab, M.C. Adeyeye, Elucidation of solution state complexation in wet-granulated oven-dried ibuprofen and $\beta$-cyclodextrin: FT-IR and H- ${ }^{1}$ NMR studies, Pharm. Dev. Tech 6 (2001) 315-324.

[27] L.S. Koester, C.R. Xavier, P. Mayorga, V.L.Bassani, Influence of $\beta$-cyclodextrin complexation on carbamazepine release from hydroxypropyl methylcellulose matrix tablets, Eur. J. Pharm. Biopharm. 55 (2003) 85-91.

[28] I. Oh, M.-Y. Lee, Y.-B. Lee, S.-C. Shin, I. Park, Spectroscopic characterization of ibuprofen/2hydroxypropyl- $\beta$-cyclodextrin inclusion complex, Int. J. Pharm. 175 (1998) 215-223.

[29] D. Bongiorno, L. Ceraulo, M. Ferrugia, F. Filizzola, A. Ruggirello, V. Turco, Inclusion complexes of cyclomaltooligosaccharides (cyclodextrins) with melatonin in solid phase, Arkat USA, inc, ISSN 1424-6376, Arkivoc XIV (2005) 118-130.

[30] Y. Tozuka, T. Fujito, K. Moribe, K. Yamamoto, Ibuprofen-Cyclodextrin inclusion complex formation using supercritical carbon dioxide, J Incl. Phenom. Macrocycl. Chem. 56 (2006) 3337.

[31] R. Cassela, D.A. Williams, S.S. Jambhekar, Solid-state $\beta$-cyclodextrin complexes containing indomethacin, ammonia and water. I. Formation studies, Int. J. Pharm. 165 (1998) 1-14.

[32] K.J. Waleczek, H.M. Cabral Marques, B. Hempel, P.C. Schmidt, Phase solubility studies of pure (-)- $\alpha$-bisabolol and camomile essencial oil with $\beta$-cyclodextrin, Eur. J. Pharm. Biopharm., 55 (2003), 247-251.

[33] H.J. Scheneider, F. Hacket, V. Rüdiger, NMR Studies of Cyclodextrins and Cyclodextrins Complexes, Chem. Rev. 98 (1998) 1755-1785.

[34] M. Másson, J.F. Sigurjónsdóttir, S. Jónsdóttir, T. Loftson, Examination of ${ }^{19}$ F-NMR as a tool for investigation of drug-cyclodextrin complexes, Drug Dev. Ind. Pharm. 29 (2003) 107-112.

[35] P. Mura, G.P. Bettinetti, A. Manderioli, M.T. Faucci, G. Bramanti, M. Sorrenti, Interactions of ketoprofen and ibuprofen with $\beta$-cyclodextrins in solution and in the solid state, Int. J. Pharm. 166 (1998) 189-203.

[36] K. Hussein, M. Türk, M.A. Wahl, Comparative evaluation of ibuprofen/cyclodextrin complexes obtained by supercritical carbon dioxide and other conventional methods, Pharm. Res. 24 (2007) 585-592.

[37] J.M.C. Leite Pinto, H.M. Cabral Marques, Anti-asthmatic-cyclodextrin inclusion complex for pulmonary delivery. STP-Pharma Sci. 9 (1999) 253-256.

[38] A. Fini, M.J. Fernandez-Hervàs, M.A. Holgado, L. Rodriguez, C. Cavallari, N. Passerini, O. Caputo, Fractal analysis of $\beta$-cyclodextrin-indomethacin particles compacted by ultrasound, J. Pharm. Sci. 86 (1997) 1303-1309. 